\title{
O COTIDIANO DO SER-ADOLESCENDO COM AIDS: MOVIMENTO OU MOMENTO EXISTENCIAL?a
}

\author{
(Cotidiano do ser-adolescendo com AIDS: movimento existencial) \\ The daily life of adolescents with aids: existential \\ movement or moment?
}

\author{
El cotidiano del ser-adolecer con sida: ¿movimiento \\ o momento existencial?
}

\author{
Cristiane Cardoso de Paula ${ }^{1}$
}

Ivone Evangelista Cabral²

Ívis Emília de Oliveira Souza ${ }^{3}$

\begin{abstract}
RESUMO
As crianças com AIDS por transmissão vertical transitam da infância para adolescência, e pouco se sabe sobre como cuidam de si. Compreender este cotidiano do adolescer foi o objetivo desta investigação fenomenológica com análise hermenêutica heideggeriana. A entrevista com 11 meninos/meninas (12-14 anos) não institucionalizados, que conheciam seu diagnóstico, ocorreu depois da aprovação do projeto pelo Comitê de Ética de três instituições do Rio de Janeiro, cenários da pesquisa. Os resultados apontaram um cotidiano marcado pelos momentos infância e adolescência. Às vezes quer voltar a ser-criança para brincar; se re-conhece como ser-adolescente pela aparência, humor, atividades diárias, lazer e relacionamentos. Transitando entre esses momentos, re-vela-se como ser-adolescendo. Neste movimento existencial des-vela-se como ser-de-possibilidades, que não está limitado à dupla-facticidade: adolescer (segundo demarcações etárias e características predeterminadas) e AIDS (fragilidade clínica). Portanto, conjugar as dimensões biológica e existencial, no modelo assistencial-institucional, é o desafio do cuidado ao ser-adolescendo.
\end{abstract}

Palavras-chave: Saúde do Adolescente. Saúde da Criança. Enfermagem Pediátrica. Síndrome de Imunodeficiência Adquirida.

\begin{abstract}
Children with vertical transmission HIV pass from childhood to adolescence and little is known about how they care for themselves. The objective was to understand the daily life of adolescents with AIDS. Heiddeger's hermeneutic analyzes was applied. The phenomenological interview of 11 noninstitutionalized boys and girls (12-14 years) with a disclosed diagnosis took place in 3 reference healthcare facilities in Rio de Janeiro. The comprehensive analysis showed that adolescents' daily live is marked by childhood and adolescent moments. In childhood, there is a desire to play like other children. In adolescence, there is a desire to be like others in appearance, mood, daily activities, leisure and relationship. In passing between these two moments, a process of becoming adolescent is revealed. In this existential movement they reveal as a beingwith-possibilities that are not limited in the double-facticity: adolescence (according to etaria marks and predetermined characteristics) and AIDS (clinical fragility). Therein resides the challenge of conjugating biological and existential dimensions in adolescent care.
\end{abstract}

Keywords: Teen Health. Child Health. Pediatric Nursing. Acquired Immunodeficiency Syndrome.

\section{Resumen}

Los niños con Sida por transmisión vertical, transitan de la infancia para la adolescencia, y poco se sabe sobre cómo cuidan de si. Comprender este cotidiano del adolecer con Sida fue el objetivo de esta investigación fenomenológica bajo el analisis de la hermenéutica heideggeriana. La entrevista con 11 niños y niñas (entre 12y 14 años), que conocían su diagnóstico y estaban no-institucionalizados, se realizó después de que el Comité de ética aprobó el proyecto de pesquisa de tres instituciones de Rio de Janeiro, escenarios de esta investigación.. Los resultados apuntaron que el cotidiano del adolecer está marcado por momentos de infancia y adolescencia. A veces quiere volver a ser-niño para jugar, y se re-conoce como ser-adolescente en la apariencia, humor, actividades diarias, ocio y relacionamientos. Transitando entre estos momentos, se re-vela como un ser-adolecer. En este movimiento existencial se re-vela como un ser-deposibilidades, que no está limitado a este doble acontecer : adolecer (según demarcaciones de la edad y características predeterminadas) y Sida (fragilidad clínica). Ahí reside el desafío de conjugar la dimensión biológica y existencial, en un modelo asistencial-institucional de cuidado al ser-adolecer .

Palabras clave: Salud del Adolescente. Salud del Niño. Enfermería Pediátrica. Síndrome de Inmunodeficiencia Adquirida.

Enfermeira, Mestre em Enfermagem pela Escola de Enfermagem da Universidade Federal do Rio Grande do Sul (UFRGS/RS/BR), Doutoranda pela Escola de Enfermagem da Universidade Federal do Rio de Janeiro (UFRJ/RJ/BR), Professora no Departamento de Enfermagem da Universidade Federal de Santa Maria (UFSM/RS/BR) na área de saúde da Criança e do Adolescente. Líder do Grupo de Pesquisa Cuidado às Pessoas, Famílias e Sociedade (UFSM) e Membro do Núcleo de Pesquisa em Saúde da Criança (UFRJ). Brasil. E-mail: ccpaula@smail.ufsm.br, ${ }^{2}$ Enfermeira, Doutora pela Universidade Federal do Rio de Janeiro (UFRJ/RJ/BR). Pós-Doutorado na McGill University (Canadá). Professora Associada do Departamento de Enfermagem Materno-Infantil da Escola de Enfermagem Anna Nery (UFRJ). Pesquisadora do CNPq e Núcleo de Pesquisa de Enfermagem em Saúde da Criança (UFRJ). Diretora do CEPEn da ABEn-Na. Orientadora da Tese. Brasil. E-mail: icabral44@hotmail.com ${ }^{3}$ Enfermeira, Doutora pela Universidade Federal do Rio de Janeiro (UFRJ/RJ/BR). Professora Titular do Departamento de Enfermagem Materno-Infantil da Escola de Enfermagem Anna Nery (UFRJ). Membro do Núcleo de Pesquisa de Enfermagem em Saúde da Criança (UFRJ) e Membro da Diretoria Colegiada do Núcleo de Pesquisa de Enfermagem em Saúde da Mulher (UFRJ). Co-orientadora da Tese. Brasil. E-mail: ivis@superig.com.br 


\section{INTRODUÇÃO}

Nesses 27 anos de epidemia no Brasil, houve investimento crescente para dar conta do agente etiológico da AIDS, na busca da garantia da sobrevivência, diante da ausência de cura. Assim, um grupo de crianças infectadas por transmissão vertical do HIV não morreu. Muito pelo contrário, venceu a etapa da infância adentrando em uma nova fase do desenvolvimento humano. Esse grupo é conhecido como a primeira geração que nasceu infectada pelo HIV e está adolescendo com AIDS.

No entanto, percebe-se que o foco da atenção está direcionado mais para as doenças do que, propriamente, para a criança doente em transição para a adolescência, aqui denominado ser-adolescendo. A pouca literatura que 0 contemplam ${ }^{1-7}$ se soma ao desconhecimento da disponibilidade de estudos que abordam a dimensão existencial ${ }^{8}$ desse novo grupo infantil no contexto social brasileiro.

Na pluralidade das pessoas doentes de AIDS, parece que a singularidade do ser-adolescendo se perde no emaranhado da importância de investigar as questões clínicas e epidemiológicas. 0 modo de vivenciar os desafios, medos e dificuldades/ facilidades; de pensar como foi sua infância nas interfaces com a AIDS; como está sendo seu dia-a-dia; e como está cuidando de si perdem relevância no confronto com as questões da pluralidade. Entretanto, a adesão à terapêutica medicamentosa e de outras questões dos cuidados de saúde são diretamente dependente da singularidade e do modo que cada um confere sentido ao seu viver no cotidiano.

Sendo assim, constitui-se o objeto de estudo o cotidiano do adolescer com AIDS no cuidado de si. Nesse sentido, procuramos nesse artigo compreender o cotidiano do ser na transição da infância para adolescência e as implicações de se ter AIDS, tanto para o cuidado de si como para o processo assistencial institucional.

\section{PER-CURSO METODOLÓGICO}

A investigação de natureza qualitativa, com abordagem fenomenológica e referencial teórico-metodológico de Martin Heidegger, ${ }^{9}$ foi desenvolvida com 11 meninos e meninas na faixa etária de 12-14 anos, que conheciam o seu diagnóstico, não estavam institucionalizados e eram atendidos em três serviços de referência no Rio de Janeiro devido a infecção por transmissão vertical do HIV.

Após a aprovação do projeto de pesquisa pelos Comitês de Ética em Pesquisa das três instituições cenários do estudo*, desenvolveu-se a etapa de campo, que se cumpriu com a proteção dos depoentes quanto aos princípios de: voluntariedade, autorização em participar da pesquisa por um responsável legal, autonomia no assentimento, anonimato, sigilo diagnóstico, confidencialidade das informações da pesquisa, justiça, equidade, diminuição dos riscos e potencialização dos benefícios, resguardando sua integridade física-mental-social de danos temporários e permanentes.

Utilizaram-se a ambientação ${ }^{10}$ e a entrevista fenomenológica, ${ }^{11}$ por meio de relação empática ${ }^{12}$ e intersubjetiva, ${ }^{13}$ indo além do aparente para captar significados, de modo a construir possibilidades assistenciais que valorizem o ser-adolescendo com AIDS.

A partir da leitura e escuta atentiva dos depoimentos, foram desenvolvidos os dois momentos metódicos do referencial heideggeriano ${ }^{9}$ : a compreensão vaga e mediana (dimensão ôntica) e a compreensão interpretativa (dimensão ontológica).

Compreender, para Heidegger, é captar os significados como modo de ser; portanto, esse processo de análise inicia-se explicitando o fato (ôntico); ou seja, o quê do ser mostra, diretamente e na maioria das vezes, no cotidiano. A análise compreensiva começa pela busca das estruturas essenciais (significantes).

Foi desenvolvido o exercício de distinção entre o que se manifestou como essencial e como ocasional/acidental. Ou seja, buscou-se o invariante, o que permanece e aponta significados que expressam o quê/como o fenômeno é.

As estruturas significantes, extraídas dos depoimentos, constituíram as Unidades de Significação (US). A partir das quais se desenvolveu o discurso fenomenológico, descrevendo os significados de estar adolescendo e ter AIDS. As US compuseram o fio condutor da análise interpretativa. Assim, por meio da hermenêutica, retirou-se de seu velamento (descobriu-se) alguns sentidos. Des-velaram-se facetas do fenômeno (ontológico) - que não se mostra diretamente, nem em sua totalidade -, e indicaram-se possibilidades de cuidado de si e de assistência em saúde aos adolescentes.

\section{COMPREENDENDO OS SIGNIFICADOS DO COTIDIANO DO ADOLESCER COM AIDS}

O ser adolescendo, em seu cotidiano, anuncia quem/como ele é, e o que é ele. Ao mostrar-se como "eu" em sua história de vida, nos diz que está vivenciando o adolescer com AIDS em toda sua singularidade, sendo que seu adolescer está marcado por dois momentos, o da infância e da adolescência. Esses momentos não se configuram como demarcações cronológicas, pois o ser transita entre ser-criança e ser-adolescente que tem a AIDS como algo permanente no seu agora.

Às vezes ainda quer ser CRIANÇA, demonstra vontade de voltar à infância e de poder brincar como antes. Expressa que ser criança é bom e que, mesmo sabendo que sempre chega a hora de crescer, tem dificuldades com as "perdas" e com a maneira que todos passam a tratá-lo. 
cotidiano do ser-adolescendo com AIDS

Paula CC, Cabral IE, Souza IEO

queria ficar sendo criança, voltar a ser criança [...] quando a gente começa a ficar grande, tem dificuldade de brincar [...] os outros ficam zoando, tipo 'criancinha, criancinha' (C6)

assim, deixar de ser criança [...] faz parte de crescer, uma hora sempre chega (C10)

Ao se re-conhecer como ADOLESCENTE, se vê em meio a tudo que faz parte disso que está vivendo: a adolescência, e considera que o que está acontecendo é igual ao que acontece com todos. Faz tudo que os(as) garotos(as) fazem, vai a balada, se veste como eles(as) gostam, mexe na internet, assiste televisão, escuta música, responde às implicâncias dos outros adolescentes e à "pegação no pé" da família.

eu sou uma adolescente meio rebelde, que faz tudo que as garotas fazem, quero sair de noite, ir para balada [...] toda garota quer usar minissaia, top, short para chamar a atenção, eu também era uma dessas garotas, atégosto de uma saia curta mesmo para mostrar as pernas que eu nem tenho [risada] (C3)

Está adquirindo experiência, aprendizado, maturidade; conquistando liberdade e privacidade. Precisa ter mais responsabilidade consigo, tendo juízo, para fazer o que tem que ser feito e como tem que ser feito, e cuidando mais de si; e com a família, ajudando em casa e obedecendo aos pais.

tem que ter responsabilidade com as coisas [...] Não deixar de fazer aquilo que tenho que fazer, né? (C8)

Crescer e "entrar na carreira de adolescente" é bom e chato ao mesmo tempo, e algumas coisas são difíceis. Nesse momento de descobertas, considera que as pessoas são diferentes e precisam adquirir suas próprias atitudes.

eu conseguiperceber que eu não era diferente de ninguém, mas não era igual a todo mundo, porque ninguém é igual;para mim, eu não sou igual a ninguém [...] às vezes tento me comparar com outras garotas, mas percebo que eunão posso fazer isso. Eu tenho que ter minha própria atitude (C3)

Vive essa alternância entre ser-criança e ser-adolescente, pois entende que tem que ser assim. Ao se apresentar dessa forma, se anuncia como um SER-ADOLESCENDO.

Percebe que conforme vai crescendo, tudo vai mudando, inclusive o jeito de ser. Percebe-se, ora de um modo, ora de outro: maduro/infantil; bonito/feio. Tem momentos em que é rebelde, preguiçoso, vaidoso, e sente que fica nervoso. às vezes eu sou madura, às vezes infantil [...] nem sempre você se acha bonitona [...] mas agora eu me acho um pouco mais [silêncio] nem tanto $G B$ (modelo fotográfico), mas não $B$.-feia (personagem de novela), antes eu me achava assim, como se tivesse sido cuspida pela minha mãe [risada] mas atéque agora eu me acho mais bonita, mais sensual [...] eu sou uma preguiçosa [...] às vezes dá ataque de aborrescente (C3)

Considera as pessoas com quem mora e que lhe cuidam: mãe e/ou pai e irmãos, como sua família, mas também se relaciona com outros familiares. Compreende que a família é importante em sua vida e estabelece com eles uma relação de amor, respeito e obediência. Porém, não gosta quando se metem em sua vida.

Entre todos os membros da família, considera a mãe como especial e estabelece com ela uma relação de ajuda, um cuidando do outro. Se a mãe já faleceu, alguém assume o cuidado, podendo ser a avó, tia ou madrasta. Reconhece como mãe aquela pessoa que assume o seu cuidado no lugar da mãe biológica, mas, quando não há o mesmo sentimento materno e nem há afinidade, tem dificuldades para se relacionar e não consegue chamá-la de mãe. Por vezes, se sente só.

eu tenho a minha tia, mas não tenho muita afinidade, muito sentimento por ela [pausa na fala] não consigo chamar ela de mãe, como a minha mãe, entendeu?[...] eu sou muito sozinha [lágrimas rolam pelo seu rosto] é dificil [pausa na fala] (C2)

a minha avó, que é quem me cuida, que é a minha mãe mesmo [...] (C6)

agora é eu e a minha mãe, minha mãe e eu [...] já somos como uma guerreira, jál Porque o que a gente jápassou [pausa na fala] tanta coisal [...] hoje ela táme ajudando, e amanhã eu quero ajudar ela [...] tratar ela como se fosse uma rainha (C9)

Tem amigos, que são aqueles que querem o seu bem e com quem pode contar sempre. Com muitos ou poucos amigos, 0 que importa é serem unidos. Relaciona-se com eles(as) na escola e/ou pela internet. Juntos, gostam de "curtir", fazer coisas de adolescentes: rir, implicar uns com os outros, ajudar uns aos outros, jogar, ir a lan house, conversar sobre a escola, sobre garotos(as) e sobre as coisas que gostam de fazer.

Tem outros garotos(as) com quem também se relaciona, mas "só de vista", que só querem se divertir; mesmo não os considerando como amigos, tenta se dar bem com todos que estão a sua volta.

...amigo para mimé a coisa mais preciosa que tem, pode contar sempre [...] a gente fala sobre garotos, 
sobre tudo, a gente fica encarnando uma na outra, rindo demais. (C3)

...meus colegas vêm e dizem tudo para mim, écomo seu eu fosse a estrela, tipo psicóloga. Lána escola, eu tenho que ajudar todo mundo, resolver os problemas de todo mundo. E, isso émuito bom! [...] alguns eu não gosto, assim, só de vista, mas têm outros que eu me dou superbem, tem uma das minhas amigas, que a gente fica se falando pelo computador [...](C7)

Mostra a importância da escola na sua transição da infância para adolescência, pois é onde tem a oportunidade de sercriança, nas brincadeiras com os colegas; e de ser-adolescente, na relação com garotos(as), conversando e trocando olhares. Étambém onde aprendem muitas coisas. Por tudo que considera "legal", mesmo quando não gosta de estudar, adora a escola.

Mas tem situações que são ruins na escola: quando os colegas "zoam" por sua imagem (o físico), por ser considerado(a) "mauricinho/patricinha", por não se misturar com aqueles que fumam/bebem ou fazem outras coisas que consideram "erradas", por estar "repetindo de ano", entre outros. Alguma(s) vez(es) teve que mudar de escola pela maneira que a tratavam, com diferença.

...eu agora não tô na escola [silêncio]. Naquela escola, eu passeipara terceira série sem saber ler [silêncio]. Lá os meninos ficam sempre zoando comigo [lágrima nos olhos]. Eles dizem: 'você é toda gorda, cheia de estrias [silêncio]'. Aía minha mãe disse que ia me tirar de lá $[. .].(\mathrm{C} 1)$

...(na escola) a gente zoa muito [...] a gente fica pulando, brincando de pique-esconde. Pôxa, a gente vira mesmo criança lá naquela escola. Émuito bom [...] a escola é tudo pra mim [...] é todo mundo me chamando, e isso me diferencia [...] aívem aqueles garotos, que são muito fofos, lindos [risada] a gente fica lá olhando para eles [...] (C3)

Descreve seu dia-a-dia referindo que é comum, como de qualquer outro, com aquilo que tem que fazer (ir para escola, fazer os deveres de aluno e ajudar em casa), e o que gosta de fazer (atividades de lazer).

Em casa, ajuda fazendo comida, lavando louça e roupa, arrumando a cama, entre outras atividades, e ajuda a cuidar dos irmãos mais novos. Sua casa é o lugar que the oferece descanso, alimentação e higiene.

Quando não está na escola, depois que faz seus deveres da escola ou de casa, ou quando está em casa, compartilha com a família e os amigos várias atividades de lazer. Em especial, compartilha com eles o assistir televisão, escutar música, jogar vídeo-game, acessar a internet, ir a festas, dançar, passeare praticar algum esporte.

...aí quando acabam as aulas eu vou para casa, aí eu tomo banho, almoço, posso descansar um pouco se eu quiser, faço meus deveres de casa, estudo, lancho, vou para academia, janto, e aí eu durmo [...] sair e curtir com os amigos e a familia (C4)

meu dia-a-dia é comum, como qualquer outro. Não tem nada de diferente assim! Eu vou para lan house, almoço, eu repito a comida duas vezes ou três [...] fico mais na lan house do que andando. Quando eu fico em casa, eu fico vendo televisão, ouvindo rádio, jogo vídeo-game (C5)

Re-conhece-se como SER-ADOLESCENDO-COM-AIDS, ao re-velar que tem um "vírus", por vezes sequer nomina o que sabe que tem. Considera ruim ter essa "doença no sangue", difícil de aceitar e encarar tudo. Mas, apesar de ser chato, enquanto não tem sintomas e não precisa internar no hospital, não é tão ruim, então nem liga, pois assim nem parece que tem esse "negócio".

Por causa desse "problema", às vezes, se acha diferente das outras pessoas, tem vergonha do que tem, e se sente triste. Não gosta de pensar muito nisso, nem de ficar falando. Tem que continuar vivendo, pensar no futuro que tem pela frente, no que é e no que pode ser, sem ficar olhando para trás e lembrando como isso aconteceu.

...poder verque eu estou bem, sabe? Perceberque eu não tenho nenhuma dificuldade com a doença que eu tenho [pausa na fala] eu ainda não tive nenhum sintoma que possa me internar. Então, para mim, tá sendo a melhor coisa! [...] teve um tempo que a gente tinha vergonha, eu tinha vergonha que eu tinha HIV, eu me achava diferente das outras pessoas [...] isso foi me deixando cada vez mais triste, para dentro de mim [...] Eu acho até que se eu não tivesse isso eu não seria a pessoa que eu sou hoje. Eu penso no meu futuro, não penso sóno passado, que lá eu peguei isso, ou no presente, sei lá, eu quero pensar sempre prá frentel Sabe, não quero ficar olhando para trás, o que eu fiz, o que teve de errado. (C3)

...[silêncio] nem seio que falar [silêncio] eu não seidizero que éque eu penso disso [silêncio] sinto que éruim [silêncio]. Éruim [silêncio] mas eu não falo (C11)

Pensa em namorar, pois reconhece que faz parte de uma época de namoro. Já beijou, "ficou", gostou de um(a) 
garoto(a) e de outro(a), e ainda vai gostar de muitos outros(as). Sobre sexo, ainda não fala, pois sente vergonha, mas está tentando descobrir.

Expressa que quer, pode e terá namorado(a). Mas tem dúvida se deve falar para o(a) garoto(a) que tem o "vírus", pois se questiona sobre qual será sua reação. A família, às vezes, diz que não pode namorar, e o ser-adolescendo acredita que isso seja uma intromissão em sua vida.

...uma época de [pausa na fala] de namoro, né?! [...] de repente eu, um dia... [pausa na fala] mas qual será a reação se eu falar para ele? [silêncio, olha para um lado, olha para cima, e com um olhar distante] é dificil( (C2)

eu não gosto muito de garoto-criança [...] ele veio me beijar, e eu 'peraí, [...] falando sério, eu não sei beijar [...] ai disse 'peraí que eu te ensino' e foi assim, comecei beijando errado [...] Quando eu tentava, eu pegada assim um gelo ou a maçã e começava a bejjar, era engraçado! [...] Esse garoto que eu fiqueié um garoto que eu comecei a gostar, só que agora eu desencanei comecei a gostar de outro [...] eu ainda sou muito nova, vou ter muitos namorados [risada] [...] falar sobre sexo, e eu fico bem assim com vergonha [...] eu já quase tentei descobrir [...] (C3)

...eu posso namorar [...] às vezes, se eu gosto de um garoto, eles (a familia) vão lá se meter, e dizem que não pode [...] poder eu posso sim [...] sóque agora eu não tenho [...] mas é claro que eu vou ter [risada] (C7)

Agora é momento de estudar. Sabe que é preciso terminar a escola, se formar, para ser independente e ter um futuro bom. Mesmo quando não gosta de estudar, sabe que precisa aproveitar este tempo para se dedicar ao estudo, fazer cursos e se preparar para trabalhar, e um dia ajudar a sua família.

$\mathrm{Na}$ escolha da profissão, reconhece que nem sempre é possível fazer o que se quer, às vezes, tem que fazer o que é possível, o que a família e/ou sua saúde permite.

...estudar, trabalhar, ajudar minha familia [...] eu preciso terminar a escola [...] quando eu for adulto eu queria ser bombeiro ou treinador de futebol. Eu queria mesmo é ser jogador [silêncio] mas eu não posso [silêncio e lágrimas nos olhos] não posso correr, se não meu coração fica acelerado [silêncio] (C6)

...são dois caminhos [silêncio] você quer ir pelo caminho bom ou caminho ruim. Ocaminho bom que é o futuro bom [...] Porque se eu for pelo caminho ruim, não vai ter futuro nenhum. [...] estudar, me formar, ser independente [...] Então se formando, você pode ter um futuro bom (C9)

\section{INTERPRETANDO OS SENTIDOS DE SER- ADOLESCENDO COM AIDS}

Esse cotidiano do adolescer com AIDS, vivido por esta primeira geração que foi infectada por transmissão vertical do HIV, aponta que o ser-adolescendo se anuncia na condição existencial de ser-aí. Assume o lugar de protagonista de suas vivências, ou seja, se coloca como "eu" no quem está vivenciando a transição da infância para adolescência, dizendo que é ele mesmo: em como se re-conhece, se relaciona e se comporta, no que tem, quer, precisa e (não) pode.

Ser-aí, "que sempre eu mesmo sou", 9:165 indica "um eu e não um outro" 9:165 0 "eu", que se re-vela presente (-aí), se comporta de diferentes maneiras em seu existir. Neste sentido, a pre-sença, na multiplicidade de modos de ser, indica continuamente o acontecer da história vivida/vivenciada por cada ser, não sendo uma construção estática.

No cotidiano, o ser-adolescendo se re-conhece como ADOLESCENTE, e re-vela que tem um vírus, mostrando-se na dupla facticidade: da adolescência e da AIDS, ou seja, desses fatos não pode fugir, pois são inerentes à sua situação de crescimento/desenvolvimento e de saúde/doença.

Portanto, a pre-sença está-lançada naquilo que já está determinado e do qual não se pode escapar. "A expressão estar-lançado deve indicar a facticidade de ser entregue à responsabilidade". 9:189 É a conotação de imposição do "ser entregue à" que é expressa pelo ser-adolecendo diante do adolescer: "acontece isso (virar adolescente) é assim e pronto"; e da AIDS: "eu peguei isso quando eu nasci [...] eu acho até que não é culpa de ninguém [...] tem que continuar vivendo assim".

É possível compreender que essa dupla-facticidade é vista sob diferentes condições: no caráter transitório de estar adolescendo, e no caráter permanente de ter AIDS. Assim, o ser-adolescendo considera que cresceré bom e ter essa doença no sangue é ruim, enfrentando essas situações de maneiras distintas.

Demonstra que, às vezes, ainda quer ser CRIANÇA, vivenciando essa alternância entre a vontade de voltar à infância e de fazer coisas de adolescente, entre as perdas e conquistas. Essa transitoriedade vivida expressa que o ser do humano se realiza como "ser-descobridor"; ;:316 e está em contínuo de vir-a-ser.

No movimento de existir-sendo, supera o imobilismo, ao conservar aquilo que já foi (passado) e ir em frente (futuro). Isso "indica a constituição ontológica do 'acontecer' próprio da pre-sença", ${ }^{(9: 48)}$ ou seja, a historicidade de cada ser.

Este vir-a-ser acontece continuamente no cotidiano que vivencia em casa, na escola e no hospital. Estes são os espaços em que o ser-adolescendo está adquirindo suas experiências, seu aprendizado e sua maturidade. Portanto, a pre-sença, ou seja, o modo pelo qual o ser-adolescendo com AIDS se mostra no cotidiano, acontece em uma espacialidade: no mundo. 
Esta espacialidade indica o "contexto em que de fato uma pre-sença vive;" ":105 sendo que ela "não apenas é e está num mundo, mas também se relaciona com o mundo" 9:164

0 relacionar-se é imprescindível para a constituição do mundo, pois este não corresponde a uma estrutura geométrica já dada, na qual o ser se localiza. 0 mundo existe somente num sistema de relações, pois isolado não é nada. ${ }^{14}$ Produz-se, somente, no estar-junto, movimento da pre-sença (distanciando/aproximando) em direção àquilo (outros ou coisas) que vem ao encontro. Assim, denota uma "estrutura fundamental da pre-sença: ser-no-mundo":75 que designa uma totalidade articulada, pois "não há mundo sem ser, como também não há ser sem mundo". ${ }^{14: 52}$

Sendo-aí-no-mundo, o ser-adolescendo se relaciona com as pessoas que integram seu cotidiano: sua família e seus pares, seja da mesma faixa etária, seja da mesma condição sorológica, e os profissionais da escola e do hospital. Também inter-age consigo mesmo. Desta maneira, mostra-se como ser-aí-com.

0 ser-com indica a natureza relacional do humano, demonstrando que "todo ser é sempre ser-com mesmo na solidão e isolamento. A pre-sença é sempre co-pre-sença, o mundo é sempre mundo-com-partilhado, o viver é sempre convivência" $9: 319$

No modo de ser-com-os-outros, o ser-adolescendo estabelece relações de diálogo, amor, respeito, obediência, ajuda, (des)confiança e curtição. Constitui, assim, o mundo público, no qual está tendo mais liberdade e responsabilidades.

Ao ser-con-sigo, se volta para seu exterior (em sua autoimagem ora bonito ora feio, em seu jeito de ser rebelde, preguiçoso, vaidoso, nervoso; e em suas atitudes ora maduro ora infantil), e para seu interior (em seus sentimentos). Neste voltar-se para si, constitui o mundo próprio, no qual está adquirindo juízo, conquistando seu espaço e cuidando mais de si.

Portanto, o ser-aí se desenvolve aí-com-os-outros e aícon-sigo no modo como se relaciona-no-mundo, "do qual resultam diversas possibilidades: mundo indica ora o público do nós, ora o circundante mais próximo e próprio". 9:105

Diante dessas possibilidades, "a pre-sença pode se comportar dessa ou daquela maneira [...] a partir de uma possibilidade própria de ser ou não ser ela mesma [...] no modo de assumir-se ou perder-se" ${ }^{1939}$. Sendo ela mesma, assume-se na singularidade do modo de ser da autenticidade; e não sendo ela mesma, perde-se na impessoalidade do modo de ser da inautenticidade.

No mundo público do nós, o ser-adolescendo se vê em meio a tudo que faz da adolescência, e diz que o que está vivendo é igual para todos. Exprime uma impessoalidade na maneira que os seres humanos se apresentam no dia-a-dia: como a gente e não como seu próprio eu. Ocorre, assim, uma "despersonalização de pessoas" 9.319 Portanto, no cotidiano "a pre-sença se relaciona com o mundo segundo um modo de ser predominante: o impessoal" 9.164 Este é, na maioria das vezes, o modo de ser da pre-sença, segundo o qual "todo mundo é outro e ninguém é si próprio."1:181

O ser-adolescendo, na relação com os outros, assume esta identidade impessoal, mostra-se como todos os adolescentes na maneira de agir, de comportar-se, na aparência, no humor, e não fala que tem o vírus.

A impessoalidade permite que ele não se diferencie das outras pessoas, pois ser considerado diferente o expõe às zoações, às implicâncias e aos rótulos, o que dificulta a convivência com as pessoas. Para que isso não aconteça, nivela-se naquilo que é comum e esperado por todos. Portanto, "enquanto ser-com, a pre-sença dá-se, essencialmente, em função dos outros". ":175

Movido pelo "empenho na con-vivência", 9:237 o seradolescendo está, quase sempre, "absorvido pelo mundo e pela co-pre-sença dos outros", 9:237 sem sequer dar-se conta que está sob o domínio da indiferenciação ${ }^{15}$. Este empenho indica a decadência da pre-sença.

De-cair na impessoalidade significa afastar-se de si (sem assumir-se em sua identidade própria), perdendo-se no todos/ ninguém (apropriando-se da identidade pública). Neste modo de ser, "permanentemente se abandona ao mundo e por ele se deixa tocar de maneira a se esquivar de si mesma". .:194

Em meio a esta cotidianidade, está lançado na facticidade das características comuns da adolescência, ou seja, não se assume na singularidade de estar adolescendo, mas na identidade de adolescente. Lançado no anonimato de sua condição sorológica, (não)mostra-se em suas atitudes: não se assume na singularidade de ter AIDS. Sequer nomina o que sabe que tem; mantém o silêncio impresso e expresso na sua historicidade desde seu nascimento. Essa facticidade está marcada pela AIDS em família.

Essas atitudes apontam o modo da inautenticidade, em que o ser-adolescendo acomoda-se sob a dependência de ser como a maioria é, não sendo ele próprio, nem entre a família, nem entre os amigos, nem no espaço da escola.

Frequentemente associada com o impessoal, a inautenticidade é o "modo de ser em que a pre-sença se mantém, na maior parte das vezes e antes de tudo". 9:168 Prescreve, portanto, o modo de ser da cotidianeidade.

Este modo de ser dominante, em que "a pre-sença, enquanto convivência cotidiana, está sob a tutela dos outros", 9:179 "vigia e controla toda e qualquer exceção que venha impor-se",, 1180 nivelando todas as possibilidades. Esta prescrição de modo de ser "retira a responsabilidade de cada pre-sença", denotando por isso a inautenticidade.

Neste modo prescrito de ser, o ser-adolescendo se encontra quase sempre envolvido com as mesmas rotinas do dia-a-dia que os seus demais colegas, e mais as demandas particulares de sua condição sorológica. Então, segundo "ocupações cotidianas de nossos hábitos", 9:154 o cotidiano lhe é familiar e nele repete sempre as mesmas coisas. Esse envolvimento com aquilo que tem que ser feito, o mantém ocupado em um modo 
de lidar com o que lhe vem ao encontro. Portanto, "o seu ser para com o mundo é essencialmente ocupação" 9:95

No entanto, apesar de estar quase sempre sob o domínio desta inautenticidade, a pre-sença nunca está irrecuperavelmente perdida neste modo de ser predominante e prescrito. Sendo assim, em alguns momentos o seradolescendo consegue se mostrar em sua singularidade, quando: expressa como se sente, compreende que precisa adquirir suas próprias atitudes e assume-se com o vírus, mesmo contando para poucas pessoas.

Ao pensar e agir por conta própria, aproxima-se do modo da autenticidade no "cumprimento-de-si-mesmo". 16:12 Esta atitude é considerada autêntica, pois, mesmo de maneira fugaz, a pre-sença recupera a responsabilidade de ser ela mesma.

No modo da autenticidade, o ser-adolescendo com AIDS abre-se para falar de si e conta sua história: desde a infecção de seus pais que resultou na transmissão vertical; as repercussões da AIDS pediátrica em sua vida e seu desenvolvimento infantil; sua transição da infância para adolescência; suas necessidades especiais de saúde; e suas possibilidades para as próximas etapas do desenvolvimento humano. Ao per-correr a estrutura triádica ${ }^{17}$ (passado, presente e futuro) de sua vida, aponta a dimensão da temporalidade.

A pre-sença possui uma determinação temporal, "sendo e estando a cada vez no tempo". 9:46 Considera-se que as dimensões da temporalidade não são localizações estáticas, pois o passado não é deixado para trás, mantém-se no presente e no futuro. Assim, a pre-sença acontece, a partir das possibilidades que pro-jeta (no por-vir) e do que aconteceu (no vivido), retroagindo no presente (nas vivências).

Neste processo de re-montar seu passado, apreender seu presente e pro-jetar seu futuro, o ser-adolescendo refere que precisa "continuar vivendo, pensarno futuro que tem pela frente, no que é eno que pode ser, sem ficar olhando para trás". Assim, mostra-se aberto às possibilidades: que quer (namoro, estudo e escolha da profissão); que precisa (tomar remédios e ir ao hospital por causa de sua doença); e que vêm ao encontro em seu vir-a-ser (contar para os outros o seu diagnóstico, casar, ter filhos, e demais situações que pode vivenciar, mas não sabe se deve). Re-vela, então, como ser-de-possibilidades.

Compreendendo-se enquanto "poder-ser", 91189 a pre-sença "doa a si mesma as possibilidades de seu ser, assumindo-as ou recusando-as" 9:190 Tem a possibilidade de ser-livre do domínio da impessoalidade (sendo-como-os-outros no mundo público) des-cobrindo-se na singularidade (sendo-si-mesmo no mundo próprio).

Portanto, o ser-adolescendo com AIDS mostra-se na dimensão existencial como ser-aí-com-no-mundo que não está preso na sua condição sorológica e nem limitado em seu desenvolvimento. Des-vela-se na vivência de seu MOVIMENTO EXISTENCIAL, e não limitado ao MOMENTO da infância/ adolescência, com suas demarcações etárias e de características predeterminadas, ou da AIDS, com suas determinações de fragilidade clínica.

\section{CONTRIBUINDO PARA O CUIDADO AO SER- ADOLESCENDO COM AIDS}

Há que se perceber que o movimento existencial vivenciado pelo ser-adolescendo com AIDS aponta como desafio para o processo assistencial: conjugar a dimensão biológica e a existencial de cuidado do ser na transição da infância para adolescência com AIDS.

Aír reside a contribuição para Enfermagem no atendimento às necessidades especiais de saúde, articulando integralidade e subjetividade. No desenvolvimento das ações de cuidado, é preciso compreender que o adolescer acontece na transição entre o momento da infância e da adolescência. Ou seja, o seradolescendo precisa ser cuidado na singularidade de seu si mesmo, e os/as enfermeiros/as não devem limitá-lo a sercriança e nem lançá-lo a ser-adolescente.

Respeitar a temporalidade do ser é uma possibilidade de aproximar-se desse modo de cuidado. Assim, ao considerar o momento da infância, a enfermagem pode utilizar brincadeiras como estratégias de acolhimento que lhe possibilite mostrarse no como se sente, precisa e quer. 0 brincar é um modo de respeitá-lo no "deixar de ser criança" em seu tempo/próprio.

Considerando o momento da adolescência, a enfermagem pode organizar o espaço do atendimento, a fim de que nele o ser-adolescendo se reconheça. Não mais um espaço para crianças, mas não ainda para adultos. Para isso, pode utilizar estratégias de encontro com os pares (da mesma condição sorológica ou não) em que possam: com-partilhar aquilo que têm de igual e diferente; trocar vivências; construindo juntos formas de enfrentamento das dificuldades do adolescer $\mathrm{e}$ adoecer.

Outra possibilidade está em considerar na historicidade as marcas da AIDS em família: o ser-adolescendo com AIDS vive desde seu nascimento infectado pelo HIV, apresenta demandas de saúde/doença, e tem seus pais, em sua maioria, também doentes. Então, seu vivido da infância sob as repercussões da AIDS, em si e na sua família, também precisa ser contemplado.

Assim, ao conhecê-lo na constituição e dinâmica familiar, saberemos como estabelece suas relações, como modo de cuidado recíproco e com-partilhado entre os familiares, ou como obediência naquilo que tem que fazer. Sabendo se o cuidado cotidiano está sendo feito para ele, com ele ou por ele, a Enfermagem pode incentivá-lo e ajudá-lo a integrar-se cada vez mais no processo de cuidar de sua saúde. Esse processo precisa acontecer sem imposições do que deve fazer, mas ajudando-o a perceber-se em suas possibilidades e limitações, e no que pode fazer diante delas.

A Enfermagem pode ajustar as prescrições conforme as atividades diárias e relações estabelecidas pelo seradolescendo, possibilitando que continue vivendo seu cotidiano e aprendendo a se cuidar. Envolvendo-se com as responsabilidades, não como um fardo (facticidade), mas como conquista (vir-a-ser), promovendo a autonomia do cuidado de si. 
Para tanto, impõe-se uma reflexão aos profissionais de saúde, em especial aos enfermeiros que se propõem a cuidar destes adolescentes com AIDS: será que as ações de saúde que estão sendo desenvolvidas estão limitadas apenas à dimensão biológica? Ou está sendo desenvolvido um olhar atentivo para ver o ser-adolescendo em sua singularidade, face as suas possibilidades de cuidado de si? São questões que deixamos aqui para a nossa reflexão e ação no cuidado de Enfermagem do ser-adolescendo no cuidado de si.

\section{REFERÊNCIAS}

1. Tavares MCT. A experiência de adolescer com AIDS [dissertação de mestrado]. Belo Horizonte (MG): Escola de Enfermagem/UFMG; 2001.

2.Souza IAA. Adolescência e soropositividade: sentidos/significado do (con)viver enquanto portador do vírus HIV [dissertação de mestrado]. Curitiba (PR): Faculdade de Psicologia/UFPR; 2003.

3.Tomaz TB. Avaliação da proteção social a população infanto-juvenil: um estudo a partir das crianças e adolescentes com HIV e AIDS [dissertação de mestrado]. João Pessoa (PB): Faculdade de Ciências Sociais/UFPB; 2003.

4.Ferreira FGF. Determinantes da adesão a terapia anti-retroviral em crianças infectadas pelo HIV [dissertação de mestrado]. Belo Horizonte(MG): Faculdade de Medicina/ UFMG; 2004.

5.Cruz EF. Espelhos d'AIDS: infâncias e adolescências nas tessituras da aids [tese de doutorado]. Campinas (SP): Faculdade de Educação/ UNICAMP; 2005.

6.Baricca AM. Vivendo e crescendo com HIV/AIDS [tese de doutorado]. São Paulo (SP): Institutos de Pesquisa da Secretaria da Saúde; 2005.

7.Lima AMA. 0 adolescer como portadora de HIV/AIDS: um estudo com adolescentes e suas cuidadoras-familiares [dissertação de mestrado]. Porto Alegre (RS): Escola de Enfermagem/UFRGS; 2006.
8.Paula CC, Crossetti MGO. A existencialidade da criança com AIDS: perspectivas para o cuidado de enfermagem. Esc. Anna Nery R Enferm 2008 jan; 12(1): 30-8.

9. Heidegger M. Ser e tempo, 1. Tradução de Márcia de Sá Cavalcante Schuback. Petrópolis(RJ): Vozes; 2002.325 p.

10.Simões SMF, Souza IEO. Um caminhar na aproximação da entrevista fenomenológica. Rev Latino-am Enfermagem 1997 jul; 5(3): 13-17.

11.Carvalho AS. Metodologia da entrevista: uma abordagem fenomenológica. Rio de Janeiro(RJ): Agir; 1987.

12.Capalbo C. Fenomenologia e hermenêutica. Rio de Janeiro(RJ): Âmbito Cultural; 1983.

13.Correa AK. Fenomenologia: uma alternativa para pesquisa em enfermagem. Rev Latino-am Enfermagem 1997 jan; 5(1); 83-88.

14.Pasqua H. Introdução à leitura de Ser e tempo de Martin Heidegger. Lisboa (PT): Instituto Piaget; 1993.

15.Dubois C. Heidegger: introdução a uma leitura. Rio de Janeiro(RJ): J Zahar; 2004.

16.Inwood M. Dicionário de Heidegger. Rio de Janeiro(RJ): J Zahar; 2002.

17. Inwood M . Heidegger. São Paulo(SP): Loyola; 2004.

\section{Nota}

a Protocolos de aprovação EEAN/UFRJ 096/06; IPPMG/UFRJ 09/07; HUGG/UNIRI0 36/07. 